\title{
Effective Removal of Alkanes and Polycyclic Aromatic Hydrocarbons by Bacteria from Soil Chronically Exposed to Crude Petroleum Oil
}

\section{Eman Afkar ( $\square$ eafkar@kfu.edu.sa )}

Dept. of Basic Sciences, Preparatory Year Deanship (PYD), King Faisal University, Al-Ahsa, 31982, Saudi Arabia. https://orcid.org/0000-0002-7442-4880

Aly M. Hafez

Dept. of Chemistry, College of Science, King Faisal University, Al-Ahsa, 31982, Saudi Arabia.

\section{Rashid I.H. Ibrahim}

Dept. of Biological Sciences, College of Science, King Faisal University, Al-Ahsa, 31982, Saudi Arabia.

Dept. of Botany, Faculty of Science, University of Khartoum, PO Box 321, PC 11115, Sudan

\section{Munirah Aldayel}

Dept. of Biological Sciences, College of Science, King Faisal University, Al-Ahsa, 31982, Saudi Arabia.

\section{Research}

Keywords: n-alkanes, GC-MS, crude oil degradation, bacteria, contaminants, hydrocarbons

Posted Date: February 16th, 2021

DOl: https://doi.org/10.21203/rs.3.rs-207407/v1

License: (c) (1) This work is licensed under a Creative Commons Attribution 4.0 International License. Read Full License 


\section{Abstract}

In this study, two bacterial strains isolated from an oil-contaminated soil, designated as AramcoS2 and AramcoS4 were able to degrade crude oil, long-chain $n$-alkanes of $\mathrm{C}_{10}$ to $\mathrm{C}_{20}$; ( $n$-decane, $n$-undecane, $n$ dodecane, $n$-tridecane, $n$-tetradecane, $n$-pentadecane, $n$-hexadecane, $n$-heptadecane, $n$-octadecane $n$ nonadecane, and $n$-eicosane) and polycyclic aromatic hydrocarbons (PAHs) including biphenyl, naphthalene, and anthracene. Gas chromatography-mass spectrometry (GC-MS) technique was conducted to analyze and identify the crude oil residues after biodegradation. AramcoS2 and AramcoS4 were able to reduce the concentration of long-chain $n$-alkanes of $C_{10}-C_{20}$ efficiently on average by $77 \%$ of the original concentration. Both isolates could also degrade PAHs on average by $67 \%$ of the original concentration within 7 and 14 days of incubation at $30^{\circ} \mathrm{C}, \mathrm{pH}=6.8 \pm 0.2$. The $16 \mathrm{~S}$ rRNA gene sequences of AramcoS2 and S4 classified these isolates as Actinobacteria; well-known alkanes and PAHs degraders. The nucleotide sequences of AramcoS2 and AramcoS4 were submitted to the GenBank database under the accession numbers MN142506 and MN142551, respectively. Both isolates can be used to restore the environments contaminated with crude oil components. They should be of great practical significance both in bioremediation of soil contaminated with crude oil and bio-treatment of oil spills on surface water.

\section{Introduction}

Biodegradation is the breakdown of organic substances by bacteria or microbes to its final products as water and carbon dioxide. Crude oil is an excellent energy source and provides starting materials for petrochemical industries. It is composed of a mixture of different hydrocarbons and non-hydrocarbon; the most commonly crude oil hydrocarbon molecules are $n$-alkanes (paraffin) represent $22 \%$, cycloalkanes (naphthenes) represent 50\%, PAHs represent 17\% (Acosta-González et al., 2015; Moubasher et al., 2015). Contamination with crude oil severely affects both human and environmental health (Bao et al., 2012; Ganesh Kumar et al., 2014; Bacosa and Inoue, 2015). Generally, the process of oil contamination is dependent on many parameters such as exploitation, transportation, and refining. When these parameters are combined with accidental spills, substantial environmental harm will happen. The high potential of environmental risks from crude oil spills encouraged us to search for local bacterial isolates inhabiting the oil-contaminated soils and able to utilize the contaminant as an energy source. Crude oil hydrocarbons ( $n$-alkanes toluene and PAHs) are prevalent organic contaminants (Lee et al., 2018; Huang et al., 2019). They are usually produced as results of the pyrolysis of organic compounds or incomplete combustion. PAHs have mutagenic, carcinogenic, and cause endocrine system problems (Dutta et al. 2017). The carcinogenic effect of those organic pollutants on body organs appears after prolonged periods of exposure (Ljunggren et al., 2014; Hernández et al., 2017; Koual et al., 2019).

Intrinsic biodegradation of crude oil was investigated in batch cultures. Short and long-chain alkanes and PAHs were the most common components of crude oil. Many organisms utilize these components as carbon and energy sources (Zawierucha et al., 2014; Adetutu et al., 2015; Ahmad et al., 2015). Despite their hydrophobicity, long-chain alkanes and PAHs can be degraded by microorganisms but at a slower rate (Chen et al. 2017b). The discovery of new genera and species of microorganisms that are capable of 
degrading crude oil is the core of petroleum microbiology. However, the Gulf area, particularly the Kingdom of Saudi Arabia is considered one of the largest countries for crude oil production; Saudi Arabia is the second-largest oil reservoir globally. Shipping and oil processing also contribute to crude oil contamination in the eastern province of Saudi Arabia. Biodegradation and Bioremediation are useful methods to remove hydrocarbon pollutants from the environment. Saudi Arabia is an oil-mining region and it faces this problem. Therefore, the significance of this work is evident. Indigenous hydrocarbon oxidizing bacteria are known to have advantages in comparison with allochthonous cultures since they are ideally adapted to the local conditions.

In the present study, the intrinsic biodegradable power of two bacterial isolates, designated as AramcoS2, and AramcoS4, was applied to degrade crude oil and PAHs. These isolates were obtained from crude oilcontaminated soil nearby Aramco petroleum aquifers located in the eastern province of Saudi Arabia. Scanning electron microscopy (SEM) of pure cultures for both bacterial isolates was captured and the $16 S$ rRNA gene sequences were amplified, sequenced, and submitted to the GenBank database. The biodegradation efficiency of both isolates understudy was investigated using GC-MS. Crude oil, longchain $n$-alkanes of $\mathrm{C}_{10}$ to $\mathrm{C}_{20}$ (decane, undecane, dodecane, tridecane, tetradecane, pentadecane, hexadecane, heptadecane, octadecane, nonadecane, and eicosane), toluene, and PAHs (biphenyl, naphthalene, and anthracene) were the subject materials.

\section{Materials And Methods}

\section{Chemicals}

Crude oil was obtained from the Saudi Arabian national petroleum and natural gas company (Aramco). Hexadecane and octadecane were purchased from BDH chemicals, England, toluene from Sigma-Aldrich Chemical Co. Germany, biphenyl from Scharlau, Spain, and naphthalene and anthracene from Lobachemie, India. Bacterial medium (mineral salt medium; MSM) components were purchased from Merk KGaA, Darmstadt, Germany.

Site description

Four soil samples were collected from the Uthmaniyah site at the Aramco gas plant area, around $35 \mathrm{~km}$ south-west of Al-Ahsa city, Saudi Arabia. Soil samples were withdrawn at different depths; 5, 15, 25, and $35 \mathrm{~cm}$ from the head well of petroleum aquifers. Uthmaniyah is located in the desert, geo-position $25^{\circ} 21^{\prime} 52^{\prime \prime} \mathrm{N}, 49^{\circ} 33^{\prime} 55^{\prime \prime} \mathrm{E}$. Climate with $83.3 \mathrm{~mm}$ of annual precipitation. The range of average temperature in summer lies between $35^{\circ} \mathrm{C}$ and $45^{\circ} \mathrm{C}$, and the winter temperatures are between $5^{\circ} \mathrm{C}$ and $25^{\circ} \mathrm{C}$.

Sampling and Enrichment of crude oil-degrading bacteria

For enrichment of bacteria, the soil samples were introduced separately to a standard mineral salt medium (MSM) containing (1 $\mathrm{gm}$ soil/100 $\mathrm{ml}$ of MSM each). The composition of the MSM was as follows: $0.2 \mathrm{MgSO}_{4}, 0.02 \mathrm{CaCl}_{2}, 1.0 \mathrm{KH}_{2} \mathrm{PO}_{4}, 1.0 \mathrm{~K}_{2} \mathrm{HPO}_{4}, 1.0 \mathrm{NH}_{4} \mathrm{NO}_{3}$, and $0.05 \mathrm{FeCl}_{3} \mathrm{~g} / \mathrm{L}$, where $\mathrm{pH}$ was 
adjusted to $6.8 \pm 0.2$. The medium was autoclaved at $120^{\circ} \mathrm{C}$ for $30 \mathrm{~min}$ and amended with a $1 \%(\mathrm{v} / \mathrm{v})$ filter-sterilized ( $0.22 \mu \mathrm{m}$ syringe filter) crude oil as the sole carbon and energy source (Parthipan Punniyakotti et al. 2017). This medium was aliquoted into $100 \mathrm{ml}$ in $250 \mathrm{ml}$ Erlenmeyer flasks and each was inoculated with $5 \mathrm{gm}$ of soil sample. The enrichment step was carried out for 7 and 14 days with continuous shaking at $30^{\circ} \mathrm{C}, \mathrm{pH}=6.8 \pm 0.2$, and $120 \mathrm{rpm}$. A control sample of $1 \%$ crude oil in the MSM was used. Ten $\mathrm{ml}$ were withdrawn from the enrichment step and transferred to a fresh MSM medium mixed with $1 \%(\mathrm{v} / \mathrm{v})$ crude oil. After a series of three further subcultures, inoculums were streaked out on MSM containing agar, and the phenotypically different colonies were characterized. The preliminary identification of the bacterial isolates was carried out based on colony appearance, shape, margin, color, and gram staining (according to Bergey's Manual of Systematic Bacteriology). The genotype identification was done using the $16 \mathrm{~S}$ rRNA sequences analyses.

Scanning electron microscopy (SEM) of AramcoS2 and AramcoS4 isolates

AramcoS2 and AramcoS4 isolates were examined using SEM. The samples were prepared by directly applying the bacterial cells onto the copper grid and allowed to dry for 2 hours then examined under a scanning electron microscope (TECHNAI10-Philips).

Sequencing of $16 \mathrm{~S}$ rRNA

Genomic DNA from single colonies of both AramcoS2 and AramcoS4 isolates were used separately as a template for PCR amplification of the 16S rRNA gene in the presence of the universal primers 27F and 1492R (Weisburg et al. 1991). The PCR reaction was carried out as follows; one cycle of DNA denaturation at $94^{\circ} \mathrm{C}$ for $45 \mathrm{~s}, 35$ cycles at $94^{\circ} \mathrm{C}$ for $45 \mathrm{~s}, 55^{\circ} \mathrm{C}$ for the $60 \mathrm{~s}$ for annealing of primers, and $72^{\circ} \mathrm{C}$ for $2 \mathrm{~min}$ as an extension step. These cycles were followed by a final elongation step at $72^{\circ} \mathrm{C}$ for $5 \mathrm{~min}$. Sequencing of DNA was performed using the Big Dye terminator sequencing kit in a 3730xI DNA analyzer (Applied Biosystems, USA) using the universal primer pair 785F and 907R.

\section{Construction of phylogenetic trees}

The sequences obtained from the 16S rRNA were edited and assembled using GENETYX software (GENETYX, Tokyo, Japan). The assembled sequences were used in BLASTN for a search of similar sequences on the NCBI (The National Center of Biotechnology Information) database. The most similar sequences were obtained and applied to MEGA7 software to build up phylogenetic relationship trees using the neighbor-joining method and bootstrap support based on 1000 replicates (Felsenstein, 1985; Saitou and Nei, 1987; Kumar et al., 2016). The evolutionary distances were computed using the Kimura 2parameter method (Kimura, 1980).

Biodegradation of crude oil

The residues of crude oil were identified by chemical analysis of a sample (Zhang et al. 2011). Four experimental sets were prepared of 100 MSM supplemented mixed with $1 \%$ crude oil for; a) AramcoS2, b) AramcoS4, c) mixed culture of AramcoS2, and AramcoS4, and d) a control set without bacteria. All four 
experimental sets were incubated at $30^{\circ} \mathrm{C}, \mathrm{pH}=6.8 \pm 0.2$ with continuous shaking at $150 \mathrm{rpm}$ for 7 and 14 days. The rate of crude oil biodegradation was monitored by extracting and measuring the concentration of crude oil residues using the GC-MS technique. Five milliliters of each treatment were extracted with 5 $\mathrm{ml}$ chloroform and shaking in a closed conical flask for 3 hours; $(1: 1 ; \mathrm{v} / \mathrm{v})$. The organic layer was collected using a separation funnel. The obtained organic extract was analyzed in Shimadzu GC-MS instrument, model QP2010 SE equipped with Rxi-5 Sil MS (30 mm length X 0.25 mm ID X $025 \mu \mathrm{m}$ film thickness) capillary column (Li et al. 2016).

One microliter from each sample was injected into the GC-MS instrument. The analysis of $1 \mu$ l of each extract was performed using the parameters of GC-MS according to the following: temperature of injector, $250^{\circ} \mathrm{C}$; starting temperature of the oven, $40^{\circ} \mathrm{C}$ (hold for $1 \mathrm{~min}$ ), then adjusted to $230^{\circ} \mathrm{C}$ at a rate of $10^{\circ} \mathrm{C}$ min-1. The overall time needed for one GC-MS run was 25 minutes. The inlet setting was the splitless mode. The line of GC-MS transfer was held at $200^{\circ} \mathrm{C}$. Highly pure helium was used as a carrier gas with a flow rate of $1 \mathrm{ml} \mathrm{min}^{-1}$. Lab Solution software (Shimadzu, Japan) was used to control the system and to report the analytical data. The obtained chromatograms were identified and the peak area of each compound was determined to measure degradation efficiency resulted from each isolate activity (AramcoS2, AramcoS4, and AramcoS2 + AramcoS4 mixture) by comparing the data to the crude oil control sample.

Biodegradation of $n$-alkanes and PAHs

To examine the degradability of isolates under study, $125 \mathrm{ppm}$ of each $n$-alkane ( $n$-hexadecane and $n$ octadecane), toluene, or PAHs (biphenyl, naphthalene, and anthracene) were injected into separate vials that contained $100 \mathrm{ml}$ of MSM and freshly harvested cells of AramcoS2 or/and AramcoS4. Treatments were kept in a dark incubator at $30^{\circ} \mathrm{C}$ and shaking at $150 \mathrm{rpm}$. Samples were collected after 7 and 14 days for analysis (Prakash et al. 2014). Three milliliters of each $n$-alkane, toluene, and PAHs were extracted with an equal volume of hexane for $30 \mathrm{~min}$. The organic phase was collected using a separation funnel and then analyzed using the same GC-MS instrument mentioned in the former section and the same parameters according to Li et al. (2016).

\section{Results And Discussion}

Isolation and preliminary identification of crude oil-degrading bacteria

Biodegradation is a widely applied technology to reduce or eliminate petroleum hydrocarbons from affected soils. It has been applied with other processes to remediate both $n$-alkanes and PAHs contaminants. These residues are degradable by many organisms as an efficient and cheap tool to remove curd oil spills. The lack of information about oil-degrading microorganisms in the eastern region of Saudi Arabia motivated us to run this research work.

Four soil samples were collected from the nearby petroleum aquifer of Aramco Company at Uthmaniyah site, eastern region, Saudi Arabia. Twenty bacterial isolates were able to grow during enrichment 
cultivation in MSM amended with $1 \%$ of crude oil as an energy and carbon source. Two isolates were able to degrade up to $80 \%$ of crude oil under experimental conditions; named AramcoS 2 and AramcoS4 for easy recognition. Colonies of AramcoS2 isolate appeared creamy in color, opaque and Gram-positive. Cells are non-motile, coccoid, measures $0.88 \mu \mathrm{m}$ in length, $0.35 \mu \mathrm{m}$ in diameter, and grow rapidly and optimally between $28-30^{\circ} \mathrm{C}$. Whereas AramcoS4 isolate is formed of small colonies, white in color, opaque, Gram-positive, slowly growing bacilli measures $1.85 \mu \mathrm{m}$ length and $0.5 \mu \mathrm{m}$ in diameter (Fig. 1).

Sequencing and phylogeny using $16 \mathrm{~S}$ rRNA

The sequences obtained from the 16S rRNA of isolates under study were used in the BLASTN search on the NCBI database. The most similar retrieved sequences were applied to MEGA7 software (Kumar et al. 2016). Based on the results of aligned sequences and phylogenetic relationships (Fig. 2) AramcoS2 isolate was found similar (99.99\%) to Georgenia daeguensis strain 2C6-43 (NR 117960.1) of the phylum Actinobacteria, a 4-chlorophenol (aromatic hydrocarbons)-degrading bacterium isolated from activated sludge during industrial wastewater treatment (Woo et al., 2012; Chen et al., 2017). Moreover, the AramcoS2 gene was also similar to that of G. soli strain C1-25C-3 (JX517240.1), and G. ferrireducens strain S61 (MG786638.1). All of these strains belong to the phylum Actinobacteria. Actinobacteria members are well-known to degrade cyclic contaminant hydrocarbons (Y. Chen et al., 2014; AcostaGonzález et al., 2015; W. Chen et al., 2017; C. Chen et al., 2020; Hu et al., 2020).

AramcoS4 isolate showed high homology with the genus Arthrobactersp. HS-NOB2 1427 (KF668242.1) (100\%), A. nicotianae strain VITNJ6 (KM047491.1), and Glutamicibacter nicotianae strain FL95 (KY849352.1). Arthrobacter is a well-known phenone and acetophenone degrading bacterium (Seo et al., 2006; Y. Chen et al., 2014). A. citrus, isolated from an organic waste-rich site, is an aerobic bacterium able to respire phenols as a sole carbon source. Recently, Zhihengliuella sp. ISTPL4 was found to efficiently degrade and detoxify phenanthrene (Karigar et al., 2006; Mishra et al., 2020). The Actinobacteria is capable of living on limited nutritional resources, resistant to drought, and has great potentials to degrade alkanes and PAHs under such conditions. This fact is in full agreement with AramcoS2 and Aramco S4 isolates since they were collected from the eastern desert of Saudi Arabia where the environment is dry and nutritional resources are limited.

Biodegradation of crude oil

The components of crude oil are more complex. Several studies documented the biodegradation of crude oil / oily sludge using single or a consortium of microorganisms (Sathishkumar et al., 2008; Hamzah et al., 2013; Q. Chen et al., 2017). Based on the analyses of the control samples in this study, it was found that the most abundant fractions in crude oil are saturated hydrocarbons, mainly $C_{10}$ to $C_{20}$ alkanes, which includes; $n$-decane, $n$-undecane, $n$-dodecane, $n$-tridecane, $n$-tetradecane, $n$-pentadecane, $n$ hexadecane, $n$-heptadecane, $n$-nonadecane, and $n$-eicosan (Fig. 3). After 7 days of incubation, the crude oil degradation was checked in the three treatments (AramcoS2, AramcoS4, and AramcoS2 + AramcoS4 mixed culture) along with the control. 
The obtained chromatograms and peak areas from the control and treatments were used to identify each compound of $\mathrm{C}_{10}-\mathrm{C}_{20}$ hydrocarbons (Fig. 4). By comparing the obtained data from the control and treatments, it was found that both isolates were able to degrade $n$-alkane hydrocarbons effectively after 7 days of incubation at $30^{\circ} \mathrm{C}$. The peak areas of $n$-decane and $n$-undecane were reduced by $85 \%$ and $64 \%$ using AramcoS2 and AramcoS4 isolates, respectively, which indicates that these isolates are very good candidates as bioremediation tools for the environment. It was also found that AramcoS2 isolate reduced the peak areas of $n$-dodecane, $n$-tridecane, and $n$-tetradecane by $87 \%, 86 \%$, and $88 \%$, while AramcoS 4 isolate reduced it by $68 \%, 68 \%$, and $66 \%$, respectively.

In the case of long-chain alkanes, i.e., $n$-pentadecane, $n$-hexadecane, $n$-heptadecane, $n$-nonadecane, and $n$-eicosan, AramcoS2 isolate reduced the peak areas by $82 \%, 81 \%, 81 \%, 75 \%$, while AramcoS 4 isolate reduced it by $71 \%, 60 \%, 56 \%$, and $56 \%$, respectively. These results clearly indicate that AramcoS2 isolate is stronger in biodegradation of long-chain alkanes than AramcoS4 isolate. In general, AramcoS2 isolate was able to degrade $n$-decane, $n$-dodecane, $n$-tridecane, and $n$-tetradecane by more than $\geq 85 \%$, while it was able to degrade the long chains of $n$-pentadecane, $n$-hexadecane, $n$-heptadecane, $n$-nonadecane, and $n$-eicosan by more than $75 \%$ but less than 85 . AramcoS 4 Isolate was able to degrade $n$-decane by $85 \%$, but reduced $n$-undecane, $n$-dodecane, $n$-tridecane, and $n$-tetradecane by $65-68 \%$ and reduced long-chain alkanes $n$-pentadecane, $n$-hexadecane, $n$-heptadecane, $n$-nonadecane, and $n$-eicosan by $56-71 \%$. The degradation efficiency seems to decrease with the increase of the alkane chain.

The mixed culture of AramcoS2 and AramcoS4 isolates reduced the peak areas of $n$-decane, $n$-undecane, $n$-dodecane, $n$-tridecane, and $n$-tetradecane by $72 \%$ and $58 \%, 65 \%, 53 \%$, and $51 \%$, respectively. Similar to the separate isolates, the degradation efficiency of the mixed isolates (S2 + S4) was lower for long-chain saturated alkanes $\left(\mathrm{C}_{15}, 32 \% ; \mathrm{C}_{16}, 22 \% ; \mathrm{C}_{17}, 16 \% ; \mathrm{C}_{19}, 13 \%\right.$, and $\left.\mathrm{C}_{20}, 11 \%\right)$. In fact, heavier hydrocarbons usually express resistance to biodegradation than light ones. Several studies have documented that longchain alkane hydrocarbons need more degradation time than short ones when a consortium of microorganisms or mixed cultures were used (Y. Chen et al., 2014; Li et al., 2016; W. Chen et al., 2017). Based on the results above, it can be stated that AramcoS2 isolate is a potential candidate tool in the field of biodegradation and soil restoration from crude oil contamination.

Biodegradation of n-alkanes

Microbial degradation of alkanes has been extensively studied; the pathways and genes involved in the degradation of alkanes are also documented (Bian et al., 2015; Laso-Pérez et al., 2019; Wang et al., 2019; Liu et al., 2019). Monooxygenases were found to be triggered by alkanes and start to oxidize the terminal methyl group to produce alcohol that is turned into aldehyde, then to a fatty acid by continuous oxidation. $\beta$-oxidation processes the fatty acid into acetyl-CoA. The degradation of alkanes by microorganisms focused on the short and medium-chain alkanes.

In this study, it was found that AramcoS2 and AramcoS4 isolates could metabolize pure $\mathrm{C}_{16}$ and $\mathrm{C}_{18}$ alkanes. AramcoS 2 Isolate degraded $85-90 \%$ of $n$-hexadecane and $80-85 \%$ of the $n$-octadecane after 7 
and 14 days of incubation (Fig. $5 a$ \& b), whereas AramcoS4 isolate degraded about $70-80 \%$ of $n$ hexadecane and $40 \%-70 \%$ of $n$-octadecane during the same incubation period. (Fig. $5 c \& d$ ).

Biodegradation of PAHs

To examine the ability of AramcoS2 and AramcoS4 isolates to utilize toluene and PAHs as energy and carbon sources, toluene, biphenyl, naphthalene, and anthracene were introduced in separate sets of experiments. The results showed that AramcoS2 isolate degraded about $94-96 \%$ of the toluene, $95-98 \%$ of biphenyl after 7 and 14 days of incubation, and degraded $91 \%$ of naphthalene after 14 days, but there was no remarkable degradation of naphthalene after 7 days. AramcoS4 isolate degrade about $73-91 \%$ of the toluene, $88-91 \%$ of biphenyl after 7 and 14 days of incubation, and degraded and $77 \%$ of the naphthalene after 14 days, but there was no remarkable degradation of naphthalene after 7 days (Fig. 6ad; Fig. 7a \& b). The degradation of anthracene by both isolates was nearly identical, i.e. $96 \%$ after 7 days and $98 \%$ after 14 days of incubation (Fig. 7c \& d).

Therefore, based on the results obtained from the degradation of crude oil, $\mathrm{C}_{16}$, and $\mathrm{C}_{18}$ alkanes, toluene, and PAHs, it was obvious that all the results are aligned together. The obtained results emphasized that both isolates, i.e., AramcoS2 and AramcoS4 are crude oil-degrading bacteria. They can also use alkanes, toluene, and PAHs to support their metabolism. Once again, the biodegradation efficiency of AramcoS2 isolate exceeds that of AramcoS4 isolate, hence, it is a potential candidate for biodegradation and soil remediation from oil contamination.

\section{Conclusion}

AramcoS2 and AramcoS4 were isolated from soil chronically exposed to crude oil spills. They were able to degrade long-chain $n$-alkanes of $\mathrm{C}_{10}$ to $\mathrm{C}_{20}$, toluene, and PAHs. They can lower the concentration of alkanes and PAHs by $77 \%$ and $67 \%$ of its original concentration. The obtained $16 \mathrm{~S}$ rRNA gene sequences placed both isolates in the phylum Actinobacteria, a well-known degrading bacteria.

\section{Declarations}

\section{Ethics approval and consent to participate}

Not applicable

\section{Consent for publication}

All authors approved the consent for publishing the manuscript to Bioresources and Bioprocessing.

\section{Availability of data and materials}

All data generated or analyzed during this study are included in this article. 


\section{Competing interests}

The authors declare that they have no competing interests.

\section{Funding}

This research work is funded by the Deputyship for Research \& Innovation, Ministry of Education in Saudi Arabia, research project grant number (IFT20116).

The role of the funder was support executing the experimental work, and publication fees as well.

\section{Authors' contributions}

EA figured out the work idea, planning, designing, and participated in executing the experimental work, cowrite the manuscript with other authors. AH designed and executed the degradation of alkanes and PAH and interpreted their results. RIH performed the analysis of Genotype of AramcoS2 and AramcoS4, cowrite and editing the manuscript. MA participated in the analysis of Genotype of AramcoS2 and AramcoS4, and finished the scanning electron microscopy work. All authors have read and approved the manuscript.

\section{Acknowledgments}

The authors are deeply grateful to Dr. Enshirah Da'na; for precise revision of the manuscript and valuable comments. Special thanks given to Mrs. Sarah M. Alsobegh for providing the crude oil samples.

\section{References}

Acosta-González A, Martirani-von Abercron SM, Rosselló-Móra R, et al (2015) The effect of oil spills on the bacterial diversity and catabolic function in coastal sediments: a case study on the Prestige oil spill. Environ Sci Pollut Res 22:15200-15214. https://doi.org/10.1007/s11356-015-4458-y

Adetutu EM, Bird C, Kadali KK, et al (2015) Exploiting the intrinsic hydrocarbon-degrading microbial capacities in oil tank bottom sludge and waste soil for sludge bioremediation. Int J Environ Sci Technol 12:1427-1436. https://doi.org/10.1007/s13762-014-0534-y

Ahmad M, Sajjad W, Rehman ZU, et al (2015) Identification and Characterization of Intrinsic Petrophilic Bacteria from Oil Contaminated Soil and Water. IntJCurrMicrobiolAppSci 4:338-346

Bacosa HP, Inoue C (2015) Polycyclic aromatic hydrocarbons (PAHs) biodegradation potential and diversity of microbial consortia enriched from tsunami sediments in Miyagi, Japan. J Hazard Mater 283:689-697. https://doi.org/10.1016/j.jhazmat.2014.09.068

Bao M tai, Wang L na, Sun P yan, et al (2012) Biodegradation of crude oil using an efficient microbial consortium in a simulated marine environment. Mar Pollut Bull 64:1177-1185.

https://doi.org/10.1016/j.marpolbul.2012.03.020 
Bian XY, Mbadinga SM, Liu YF, et al (2015) Insights into the anaerobic biodegradation pathway of nAlkanes in oil reservoirs by detection of signature metabolites. Sci Rep 5:1-12.

https://doi.org/10.1038/srep09801

Chen C, Chen S, Zhang W, et al (2020) Streptomyces sp. S501, a Marine Petroleum-Degrading Actinobacterium Isolated from Sediment of Yalujiang Estuary, Northern China, and Its Genome Annotation. Curr Microbiol 77:3643-3650. https://doi.org/10.1007/s00284-020-02181-2

Chen Q, Li J, Liu M, et al (2017a) Study on the biodegradation of crude oil by free and immobilized bacterial consortium in marine environment. PLoS One 12:1-23.

https://doi.org/10.1371/journal.pone.0174445

Chen W, Li J, Sun X, et al (2017b) High efficiency degradation of alkanes and crude oil by a salt-tolerant bacterium Dietzia species CN-3. Int Biodeterior Biodegrad 118:110-118.

https://doi.org/10.1016/j.ibiod.2017.01.029

Chen Y, Li C, Zhou Z, et al (2014) Enhanced biodegradation of alkane hydrocarbons and crude oil by mixed strains and bacterial community analysis. Appl Biochem Biotechnol 172:3433-3447. https://doi.org/10.1007/s12010-014-0777-6

Dutta T, Kwon E, Bhattacharya SS, et al (2017) Polycyclic aromatic hydrocarbons and volatile organic compounds in biochar and biochar-amended soil: a review. GCB Bioenergy 9:990-1004. https://doi.org/10.1111/gcbb.12363

Felsenstein J (1985) Confidence Limits on Phylogenies: An Approach Using the Bootstrap. Evolution (N Y) 39:783. https://doi.org/10.2307/2408678

Ganesh Kumar A, Vijayakumar L, Joshi G, et al (2014) Biodegradation of complex hydrocarbons in spent engine oil by novel bacterial consortium isolated from deep sea sediment. Bioresour Technol 170:556564. https://doi.org/10.1016/j.biortech.2014.08.008

Hamzah A, Phan CW, Abu Bakar NF, Wong KK (2013) Biodegradation of crude oil by constructed bacterial consortia and the constituent single bacteria isolated from Malaysia. Bioremediat J 17:1-10. https://doi.org/10.1080/10889868.2012.731447

Hernández ÁR, Boada LD, Mendoza Z, et al (2017) Consumption of organic meat does not diminish the carcinogenic potential associated with the intake of persistent organic pollutants (POPs). Environ Sci Pollut Res 24:4261-4273. https://doi.org/10.1007/s11356-015-4477-8

Hu J, Bao Y, Zhu Y, et al (2020) The Preliminary Study on the Association Between PAHs and Air Pollutants and Microbiota Diversity. Arch Environ Contam Toxicol 79:321-332.

https://doi.org/10.1007/s00244-020-00757-4 
Huang Y, Pan H, Wang Q, et al (2019) Enrichment of the soil microbial community in the bioremediation of a petroleum-contaminated soil amended with rice straw or sawdust. Chemosphere 224:265-271. https://doi.org/10.1016/j.chemosphere.2019.02.148

Kimura D (1980) Likelihood methods for the von Bertalanffy growth curve. Fish Bull 77:765-776

Koual M, Cano-Sancho G, Bats AS, et al (2019) Associations between persistent organic pollutants and risk of breast cancer metastasis. Environ Int 132:105028. https://doi.org/10.1016/j.envint.2019.105028

Kumar S, Stecher G, Tamura K (2016) MEGA7: Molecular Evolutionary Genetics Analysis Version 7.0 for Bigger Datasets. Mol Biol Evol 33:1870-1874. https://doi.org/10.1093/molbev/msw054

Laso-Pérez R, Hahn C, Van Vliet DM, et al (2019) Anaerobic degradation of non-methane alkanes by "candidatus methanoliparia" in hydrocarbon seeps of the gulf of Mexico. MBio 10:1-20. https://doi.org/10.1128/mBio.01814-19

Lee DW, Lee H, Lee AH, et al (2018) Microbial community composition and PAHs removal potential of indigenous bacteria in oil contaminated sediment of Taean coast, Korea. Environ Pollut 234:503-512. https://doi.org/10.1016/j.envpol.2017.11.097

Li X, Zhao L, Adam M (2016) Biodegradation of marine crude oil pollution using a salt-tolerant bacterial consortium isolated from Bohai Bay, China. Mar Pollut Bull 105:43-50.

https://doi.org/10.1016/j.marpolbul.2016.02.073

Liu YF, Qi ZZ, Shou L Bin, et al (2019) Anaerobic hydrocarbon degradation in candidate phylum 'Atribacteria' (JS1) inferred from genomics. ISME J 13:2377-2390. https://doi.org/10.1038/s41396-0190448-2

Ljunggren SA, Helmfrid I, Salihovic S, et al (2014) Persistent organic pollutants distribution in lipoprotein fractions in relation to cardiovascular disease and cancer. Environ Int 65:93-99.

https://doi.org/10.1016/j.envint.2013.12.017

Moubasher HA, Hegazy AK, Mohamed NH, et al (2015) Phytoremediation of soils polluted with crude petroleum oil using Bassia scoparia and its associated rhizosphere microorganisms. Int Biodeterior Biodegrad 98:113-120. https://doi.org/10.1016/j.ibiod.2014.11.019

Prakash A, Thavaselvam D, Kumar A, et al (2014) Isolation, identification and characterization of Burkholderia pseudomallei from soil of coastal region of India. Springerplus 3:1-10. https://doi.org/10.1186/2193-1801-3-438

Saitou N, Nei M (1987) The neighbor-joining method: a new method for reconstructing phylogenetic trees. Mol Biol Evol 4:406-425. https://doi.org/10.1093/oxfordjournals.molbev.a040454 
Sathishkumar M, Binupriya AR, Baik SH, Yun SE (2008) Biodegradation of crude oil by individual bacterial strains and a mixed bacterial consortium isolated from hydrocarbon contaminated areas. Clean - Soil, Air, Water 36:92-96. https://doi.org/10.1002/clen.200700042

Seo JS, Keum YS, Hu Y, et al (2006) Phenanthrene degradation in Arthrobacter sp. P1-1: Initial 1,2-, 3,4and 9,10-dioxygenation, and meta- and ortho-cleavages of naphthalene-1,2-diol after its formation from naphthalene-1,2-dicarboxylic acid and hydroxyl naphthoic acids. Chemosphere 65:2388-2394. https://doi.org/10.1016/j.chemosphere.2006.04.067

Wang Y, Wegener G, Hou J, et al (2019) Expanding anaerobic alkane metabolism in the domain of Archaea. Nat Microbiol 4:595-602. https://doi.org/10.1038/s41564-019-0364-2

Weisburg WG, Barns SM, Pelletier DA, Lane DJ (1991) 16S ribosomal DNA amplification for phylogenetic study. J Bacteriol 173:697-703. https://doi.org/10.1128/jb.173.2.697-703.1991

Woo SG, Cui Y, Kang MS, et al (2012) Georgenia daeguensis sp. nov., isolated from 4-chlorophenol enrichment culture. Int J Syst Evol Microbiol 62:1703-1709. https://doi.org/10.1099/ijs.0.033217-0

Zawierucha I, Malina G, Ciesielski W, Rychter P (2014) Effectiveness of intrinsic biodegradation enhancement in oil hydrocarbons contaminated soil. Arch Environ Prot 40:101-113. https://doi.org/10.2478/aep-2014-0010

Zhang Z, Hou Z, Yang C, et al (2011) Degradation of n-alkanes and polycyclic aromatic hydrocarbons in petroleum by a newly isolated Pseudomonas aeruginosa DQ8. Bioresour Technol 102:4111-4116. https://doi.org/10.1016/j.biortech.2010.12.064

\section{Figures}


AramcoS2

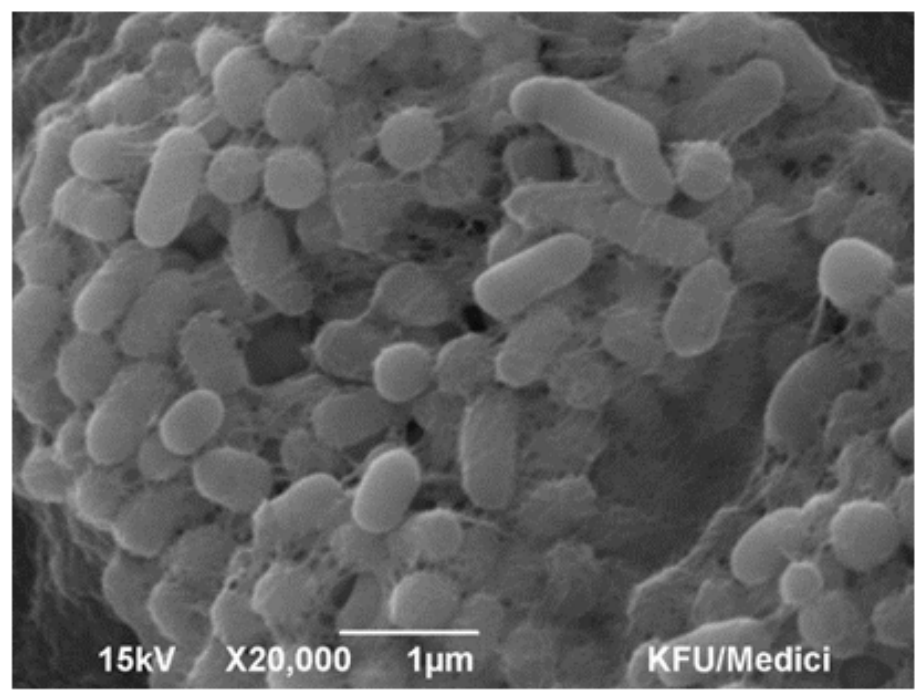

AramcoS4

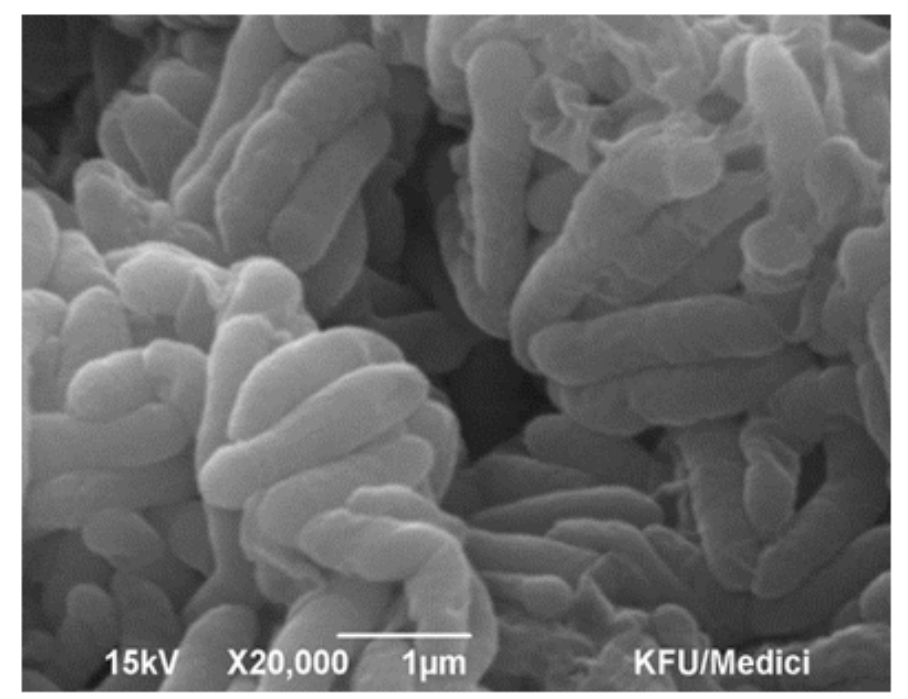

\section{Figure 1}

Scanning electron microscope images of a pure culture of bacterial isolate AramcoS2 (left) and AramcoS4 (right). Samples were stained with osmium tetroxide. AramcoS2 isolate measured $0.88 \mu \mathrm{m}$ length, $0.35 \mu \mathrm{m}$ width, whereas AramcoS 4 isolate measured $1.85 \mu \mathrm{m}$ length, $0.5 \mu \mathrm{m}$ width 


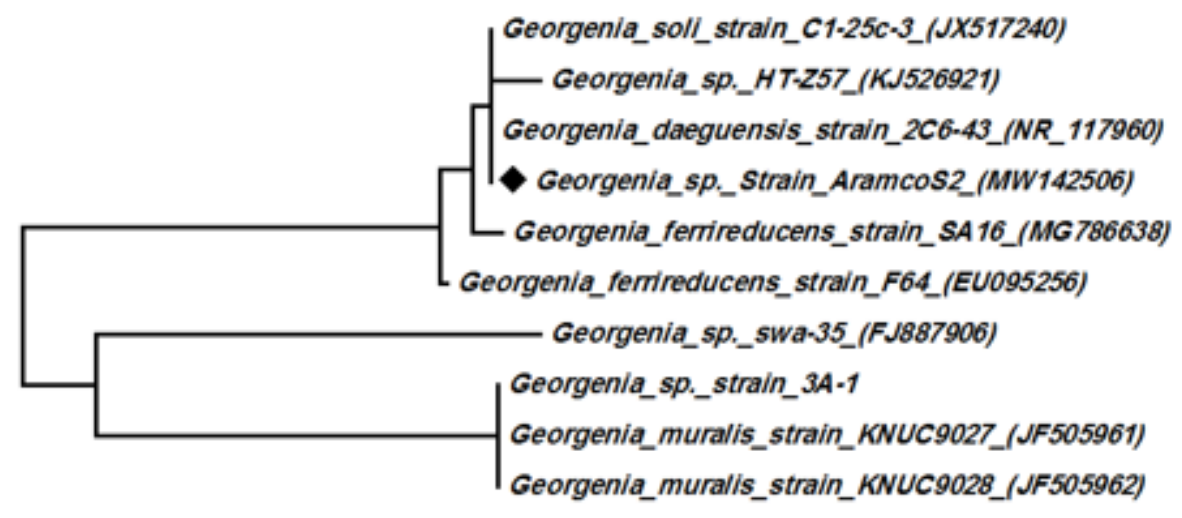

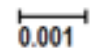

Fig. 2 (a)

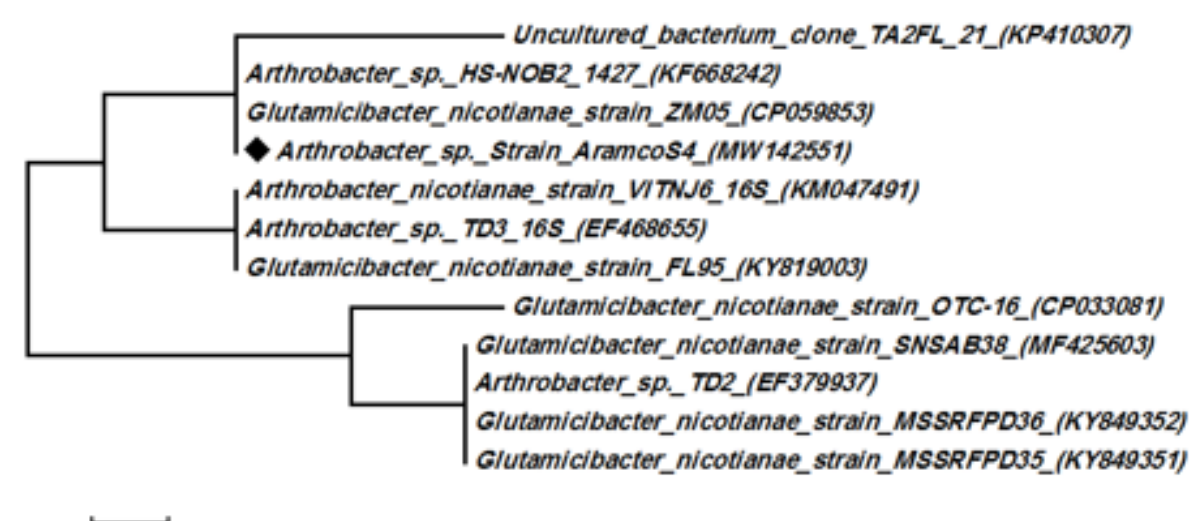

$\longdiv { 0 . 0 0 0 2 }$

Fig. 2 (b)

Figure 2

Evolutionary relationships of AramcoS2 (a) and AramcoS4 (b) bacterial isolates. The evolutionary history was inferred using the Neighbor-Joining method (Saitou and Nei, 1987). The optimal tree with the sum of branch length $=0.02229862$ for AramcoS2 or $=0.00317748$ for AramcoS 4 is shown. The trees are drawn to scale, with branch lengths in the same units as those of the evolutionary distances used to infer the phylogenetic trees. The evolutionary distances were computed using the Kimura 2-parameter method (Kimura 1980) and are in the units of the number of base substitutions per site. The analysis involved 10 of the most related nucleotide sequences retrieved from the NCBI database using the BLASTN option for AramcoS2 and 12 sequences for AramcoS4. Codon positions included were 1st $+2 n d+3 r d+$ Noncoding. All positions containing gaps and missing data were eliminated. There were 1342 for AramcoS 2 and 1418 positions for AramcoS4 in the final dataset. Evolutionary analyses were conducted in MEGA7 (Kumar et al. 2016). Accession numbers are between parenthesis: (MW142506) for AramcoS2 and (MW142551) for AramcoS4 


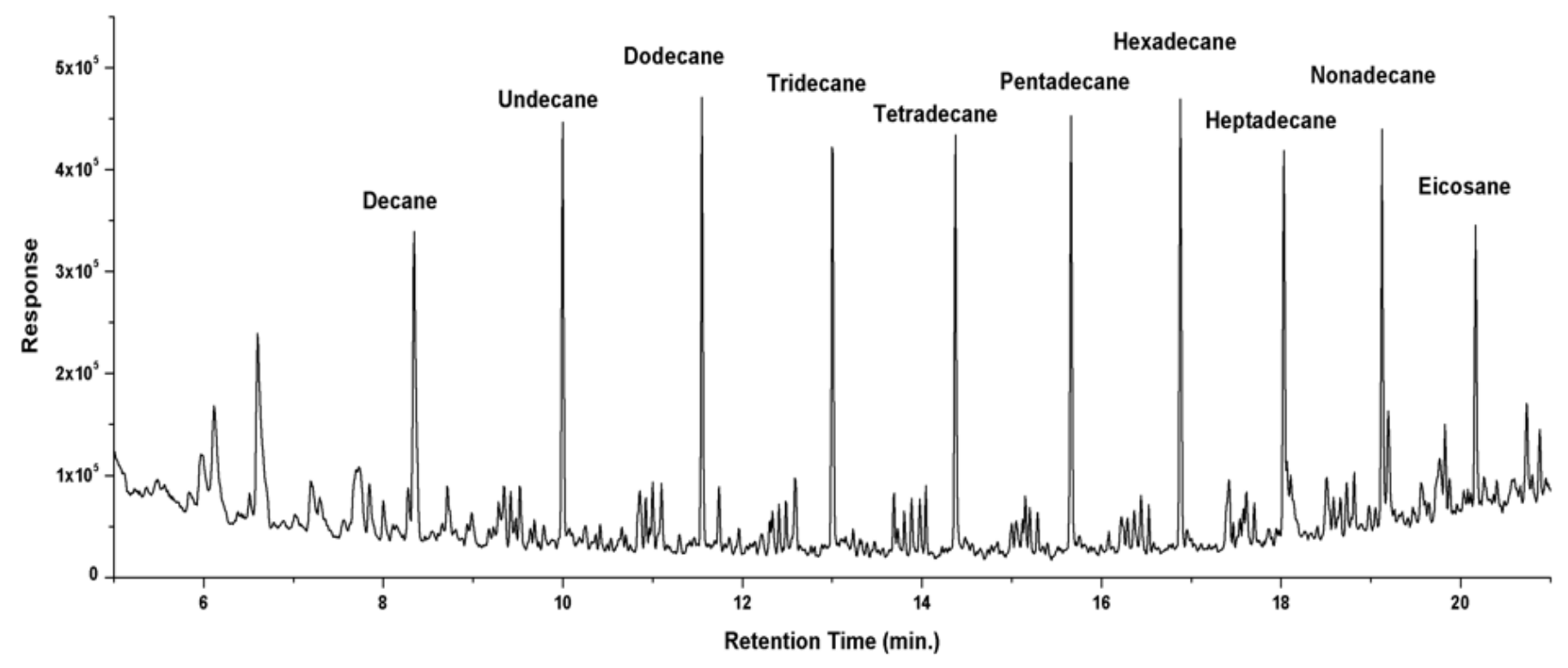

Figure 3

GC-MS chromatogram of crude oil as a control sample that identifies the major $n$-alkanes residues

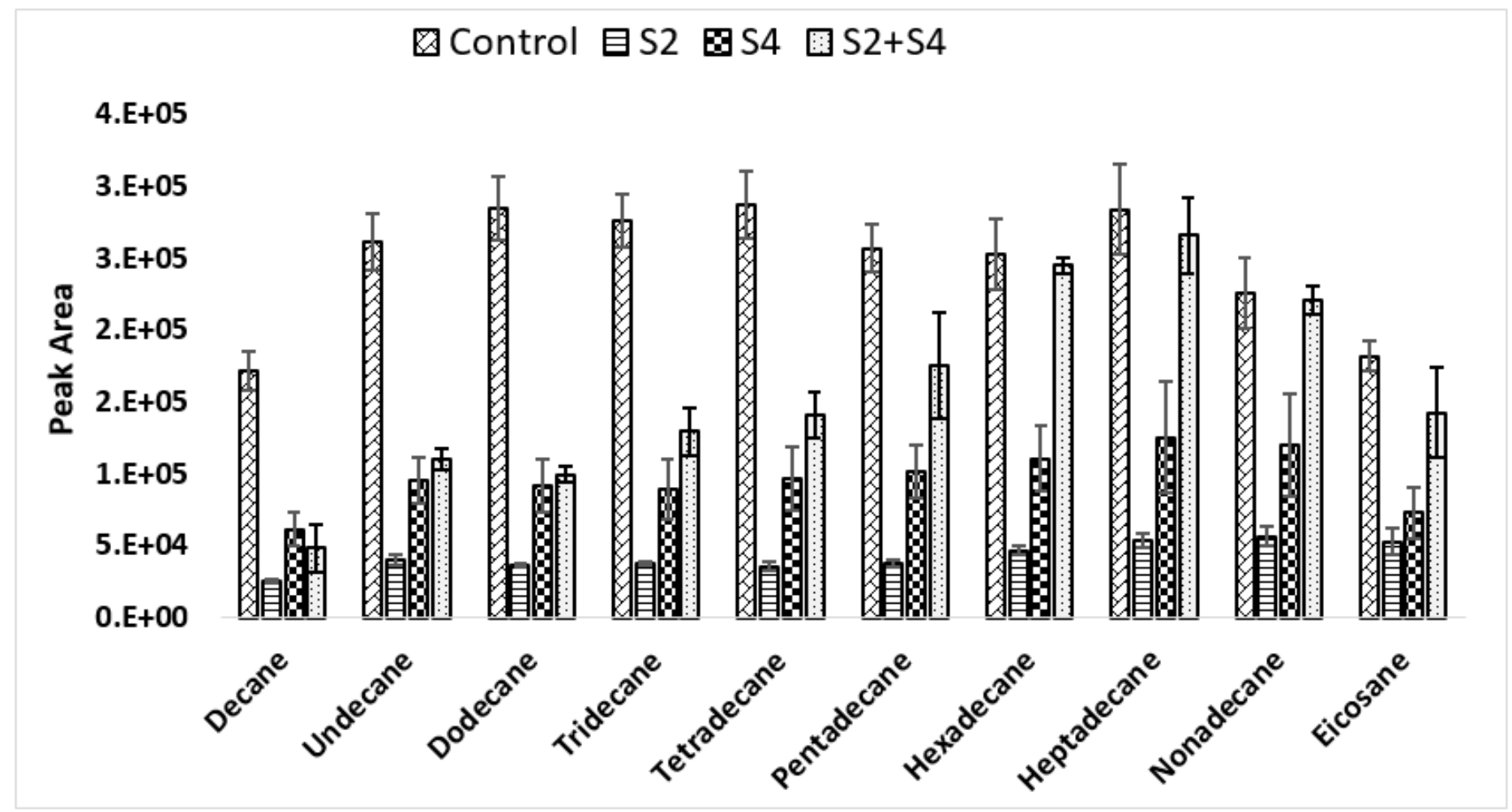

Figure 4

Average peak areas of replicated measurements $(n=3)$ of extracted residues from crude oil control samples in comparison with samples inoculated with AramcoS2, AramcoS4, and mixed AramcoS2+AramcoS4 isolates for 7 days of incubation time 

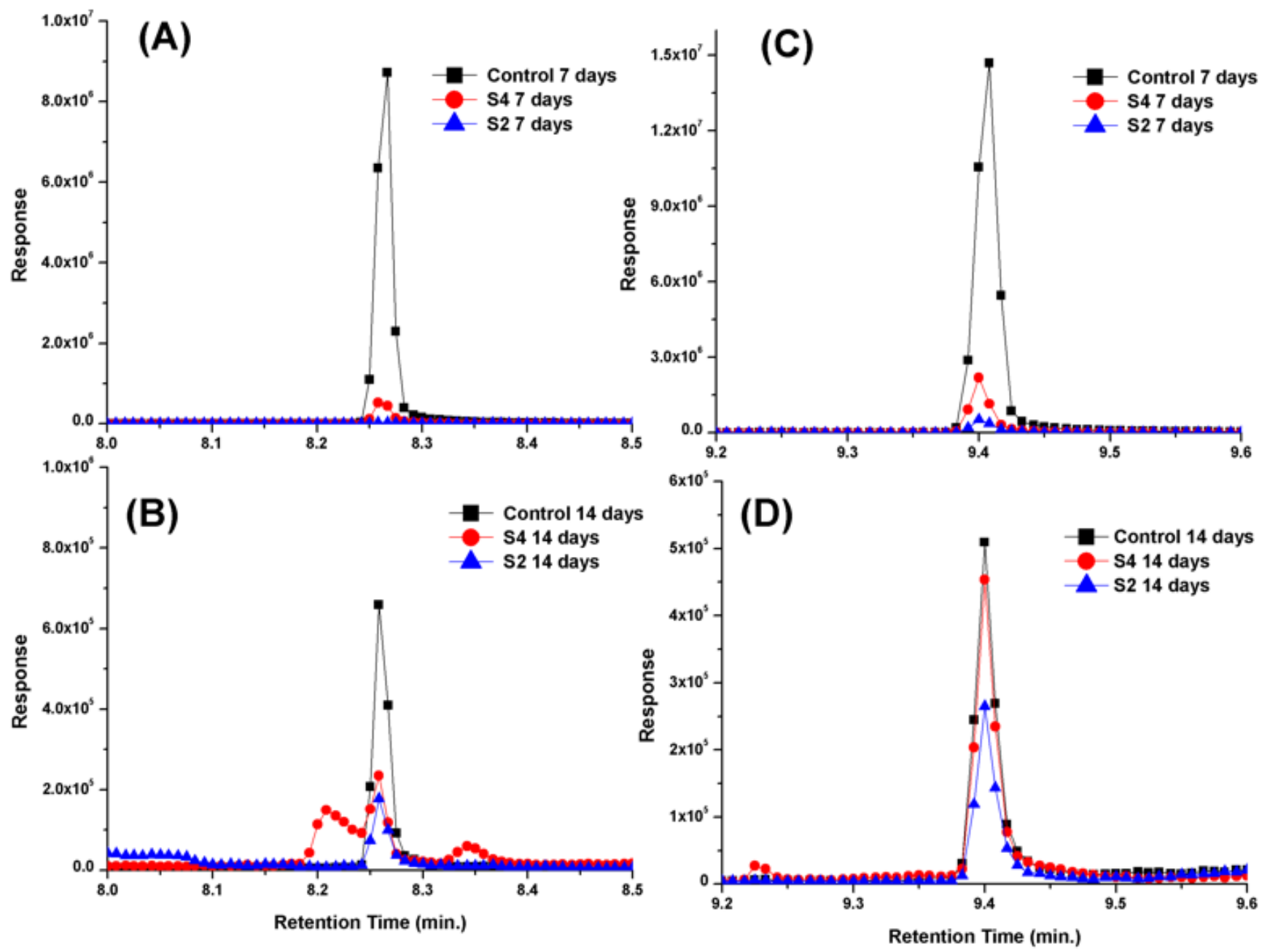

Figure 5

n-Hexadecane degradation after 7 days (a) and after 14 days (b) of incubation without or with Aramcos2, AramcoS4, or a mix of both isolates. n-Octadecane degradation after 7 days (c) and after 14 days (d) of incubation without or with AramcoS2, AramcoS4, or a mix of both isolates 

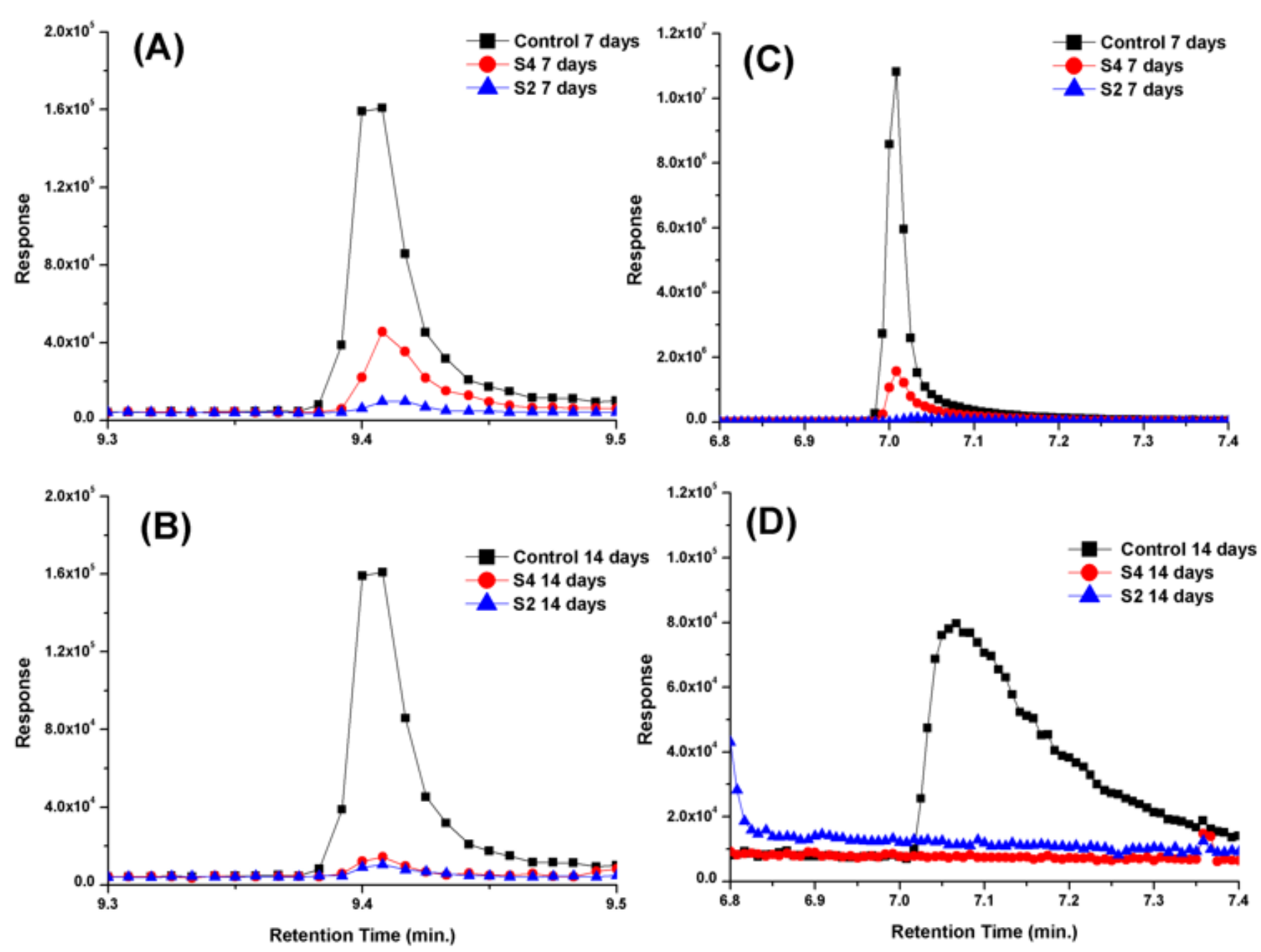

Figure 6

Toluene degradation after 7 days (a) and after 14 days (b) of incubation without or with Aramcos2, AramcoS4, or a mix of both isolates. Biphenyl degradation after 7 days (c) and after 14 days (d) of incubation without or with AramcoS2, AramcoS4, or a mix of both isolates 

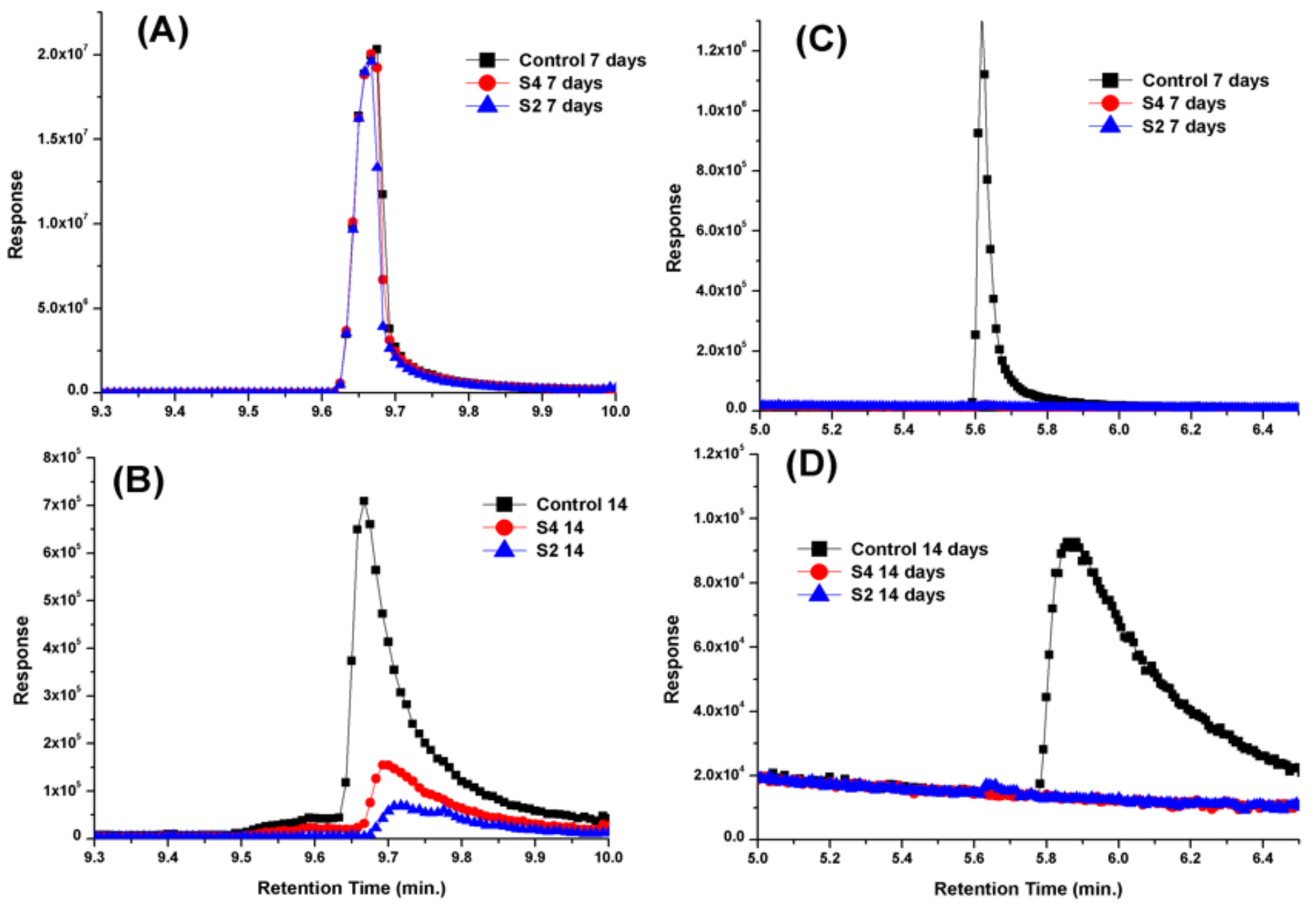

Figure 7

Naphthalene degradation after 7 days (a) and after 14 days (b) of incubation without or with Aramcos2, AramcoS4, or a mix of both isolates. Anthracene degradation after 7 days (c) and after 14 days (d) of incubation without or with AramcoS2, AramcoS4, or a mix of both isolates

\section{Supplementary Files}

This is a list of supplementary files associated with this preprint. Click to download.

- Fig.2aSupplementary.tif

- Graphicalabstract.pdf

- Fig.2bSupplementary.tif 